\title{
THE HYDROGEN EMBRITTLEMENT OF ALLOY X-750
}

\author{
Douglas M. Symons" and Anthony W. Thompson+ \\ - Bettis Atomic Power Laboratory \\ Westinghouse Electric Corporation \\ West Mifflin, Pennsylvania 15122 \\ + Lawrence Berkeley Laboratory \\ Berkeley, California 94708
}

\begin{abstract}
This study investigated the mechanism of hydrogen embrittlement in Alloy X-750 through tensile testing and fracture toughness testing. The failure mode in this material was ductile intergranular fracture through microvoid coalescence. The microvoid initiation sites appear to be the grain boundary chromium carbides based upon the size and the spacing of the microvoids as well as upon plateau etching. The elongation decreased from $21 \%$ with no hydrogen to $3.5 \%$ with $65 \mathrm{ppm}$ hydrogen at $25^{\circ} \mathrm{C}$ while no degradation was observed at $-196^{\circ} \mathrm{C}$. This suggests that the HELP mechanism plays a role in the fracture process. It was shown that prestraining, cold work, prior to charging decreased elongation. Specimens plastically strained to $5 \%$ and $10 \%$ plastic strain prior to hydrogen charging and strained to failure after the charging at a rate of $3.33 \times 10^{-4} \mathrm{~s}^{-1}$, failed near the flow stress. This is consistent with the need for local plasticity at the grain boundaries not observable in the bulk. The results of this study are consistent with the mechanism of hydrogen embrittlement as a combination of the reduction in particle interfacial energy and the HELP mechanism, though, a hydrogen pressurization mechanism or a local increase in the void growth rate can not be discounted.
\end{abstract}

\subsection{INTRODUCTION}

The effect of hydrogen on the deformation and fracture behavior of nickel-base alloys has been studied $((1),(2),(3))$. Though, there is only a small database on testing of internally gas charged $r^{\prime}$-strengthened polycrystalline nickel-base alloys. Internal hydrogen embrittlement of Alloy 903, a $r^{\prime}$-strengthened austenitic ironbased superalloy has been extensively examined by Moody et al. $((5)(6))$.

Three mechanisms have been proposed to explain the hydrogen embrittlement in nickel-base alloys. The first mechanism is a decohesion mechanism in which hydrogen decreases the cohesive energy between atoms and promotes a more brittle fracture; this was originally proposed for transgranular cleavage in steels by Troiano (7) and furthered by Oriani (8). For the microvoid coalescence process observed in this system, the concept of decohesion used to characterize the reduction in the cohesive strength of the carbide-matrix interface. The second mechanism involves the enhanced mobility of dislocations due to hydrogen as was first theorized and 


\section{DISCLAIMER}

This report was prepared as an account of work sponsored by an agency of the United States Government. Neither the United States Government nor any agency thereof, nor any of their employees, makes any warranty, express or implied, or assumes any legal liability or responsibility for the accuracy, completeness, or usefulness of any information, apparatus, product, or process disclosed, or represents that its use would not infringe privately owned rights. Reference herein to any specific commercial product, process, or service by trade name, trademark, manufacturer, or otherwise does not necessarily constitute or imply its endorsement, recommendation, or favoring by the United States Government or any agency thereof. The views and opinions of authors expressed herein do not necessarily state or reflect those of the United States Government or any agency thereof. 


\section{DISCLAIMER}

\section{Portions of this document may be illegible in electronic image products. Images are produced from the best available original document.}


experimentally shown to occur in steels by Beachem (9). This mechanism has been demonstrated by fractographic techniques and in-situ environmental-cell transmission electron microscopy (TEM) of nickel by Birnbaum $((10),(1))$ and for precipitation strengthened polycrystalline (2) or single crystal ((3), (4)) superalloys. The hydrogen enhanced local plasticity (HELP) mechanism suggests that the fracture occurs by very local plasticity. The final mechanism involves local pressurization due to hydrogen at the particle interface. This pressurization may be due to either the equilibrium pressure of hydrogen with the matrix at the interface or high hydrogen pressures due to hydrogen sweeping by dislocations and accumulation at the particle interface(16). The local pressure may reduce the stress required to initiate voids or it may increase the growth rate of the voids.

The work reported here utilized hydrogen precharged uniaxial tensile specimens and compact tension specimens to gain further insight into the hydrogen embrittlement mechanism in nickel-base superalloys. It is the goal of this work to clarify the role of hydrogen in the embrittlement of $\gamma^{\prime}$ strengthened superalloys.

\subsection{MATERIAL AND EXPERIMENTAL PROCEDURE}

The material used for this program was HTH Alloy $X-750$. The material was received in the form of $6.35 \mathrm{~cm}$ bar. The bulk composition was:

CHEMICAL ANALYSIS

Major Elements (wt \%)

\begin{tabular}{|}
\begin{tabular}{|c|c|c|c|c|c|c|c|}
\hline $\mathrm{Ni}$ & $\mathrm{Cr}$ & $\mathrm{Nb}+\mathrm{Ta}$ & $\mathrm{Ti}$ & $\mathrm{Al}$ & $\mathrm{Fe}$ & $\mathrm{C}$ & $\mathrm{B}$ \\
\hline 71.17 & 15.46 & 1.00 & 2.67 & 0.76 & 8.33 & 0.072 & 0.006 \\
\hline \multicolumn{8}{|c|}{ Minor Elements (wt. \%) } \\
\hline $\mathrm{Mn}$ & $\mathrm{Si}$ & $\mathrm{S}$ & $\mathrm{Co}$ & $\mathrm{P}$ & $\mathrm{V}$ & $\mathrm{As}$ & $\mathrm{Cu}$ \\
\hline 0.10 & 0.11 & .001 & 0.07 & .007 & 0.02 & $<10 \mathrm{ppm}$ & 0.01 \\
\hline
\end{tabular}
\end{tabular}

The mean intercept grain size of this material is $125 \mu \mathrm{m}$ as shown in Figure 2.1. There are closely spaced discrete grain-boundary carbide precipitates as depicted in the TEM micrograph of Figure 2.2. These carbides, from TEM diffraction patterns, have been identified as $\mathrm{M}_{23} \mathrm{C}_{6}$. There are also intragranular primary carbides and carbonitrides, $M(C, N)$, aligned along the rolling direction. The metal constituents in the primary carbides and carbonitrides are $\mathrm{Nb}$ and $\mathrm{Ti}$, as determined from scanning electron microscopy (SEM) energy-dispersive spectroscopy.

The tensile specimens and the 0.4T compact tension specimens were charged in a high-pressure hydrogen autoclave. The pressure used was $34 \mathrm{MPa}$ hydrogen at $360^{\circ} \mathrm{C}$ or $21 \mathrm{MPa}$ at $300^{\circ} \mathrm{C}$. Specimens were charged in the autoclave for 3 weeks. This was sufficient time for diffusion of the hydrogen through the specimen and to attain a uniform hydrogen concentration. The purpose for the lowtemperature charging was to avoid altering the microstructure and recovery processes in deformed specimens.

Subsize tensile specimens with varying amounts of dissolved hydrogen were tested as a function of test temperature $\left(-196^{\circ} \mathrm{C}\right.$ to $\left.285^{\circ} \mathrm{C}\right)$. These tests used cylindrical subsize specimens fabricated according to ASTM E8 with a nominal gage diameter of $0.635 \mathrm{~cm}$. An extensometer was used to measure the strain and to control the strain rate for all testing except the $-196^{\circ} \mathrm{C}$ testing. The testing at $196^{\circ} \mathrm{C}$ was performed at a constant displacement rate. In some instances the reduction in area could not be determined. 
The effect of cold work on the embrittlement was evaluated by using subsize tensile specimens that were strained to $1.6 \%, 5 \%$ and $10 \%$ plastic strain prior to hydrogen charging at $360^{\circ} \mathrm{C}$. After charging these specimens were strained to failure. A comparison was made of the prestrain load, the fracture load, and the fracture strain after charging.

The fracture toughness of the hydrogen-charged specimens was determined by using linear-elastic fracture toughness testing while for the noncharged specimens elastic-plastic fracture toughness testing was employed. The hydrogen-charged specimens were $0.4 \mathrm{~T}$ compact tension specimens and were tested at room temperature using loading rates that varied by a factor of 15 . The tests were run according to ASTM E399-90 to determine $K_{10}$, though the loading rates were varied. Noncharged specimens were tested using ASTM E399-90 as well as ASTM E81381. ASTM E813-81 was used instead of the more-recent E813-89 since the E81381 standard allows for the conversion of $J_{1 c}$ to $a K_{J_{c}}$. The noncharged specimens were $0.6 \mathrm{~T}$ with $20 \%$ side grooves. The side grooves were essential to obtaining valid results since this material tends to have excessive tunnelling. It was not possible to perform a $\mathrm{J}$ test on the hydrogen-charged specimens since during the hold prior to the compliance measurement stable cracking was observed.

Scanning electron microscopy (SEM) was used for both fractography and microstructural analysis. Fractographic examination was performed to evaluate the microstructural features that were important in controlling the fracture behavior. $h$ order to obtain additional microstructural information concerning the micromechanism of fracture, the plateau etching technique was employed. This technique has been successfully applied to titanium alloys (11). In some instances, duplicate specimens were tested so that one specimen could be unloaded just prior to fracture and analyzed.

\subsection{RESULTS AND DISCUSSION}

\subsection{Tensile Properties}

The results are separated into two groups: first the fracture behavior of the as received and hydrogen charged material; second, the effect of prestrain, i.e., cold work, on the fracture behavior of hydrogen charged material. Table 3.1.1 displays the results of the tensile testing. Hydrogen had very little effect on the yield strength of the alloy but there was an effect on the ductility. The lack of a yield strength affect is most likely due to the rates at which the tensile tests were conducted, which were from $3.33 \times 10^{-3} \mathrm{~s}^{-1}$ to $3.33 \times 10^{-5} \mathrm{~s}^{-1}$. A slower strain rate is required for ambient temperature testing to see an effect of hydrogen on the yield strength. Analysis of the matching fracture surfaces permitted the detailed fractographic characterization required to evaluate the fracture mechanism.

The total elongation was decreased by the addition of hydrogen. The elongation was $21 \%$ with no hydrogen and decreased to $3.5 \%$ with $65 \mathrm{ppm}$ hydrogen at room temperature. No necking was observed in these specimens. Examination of the fracture surfaces of the tensile specimens showed the fracture process to be intergranular microvoid coalescence. The grain boundary surfaces of the noncharged specimens (Figure 3.1.1) and the hydrogen-charged specimens (Figure 3.1.2) consisted of ductile dimples. Calculation of the final void diameter revealed that hydrogen had no effect on the size of the microvoids, $0.4 \mu \mathrm{m}$. The void initiation event occurred at the grain boundary carbides as is evident in Figure 3.1.3. 
TABLE 3.1.1 THE FRACTURE BEHAVIOR OF TENSILE SPECIMENS

\begin{tabular}{|c|c|c|c|c|c|}
\hline $\begin{array}{c}\text { failure strain } \\
\text { for } \\
\text { hydrogenated } \\
(65 \mathrm{ppm})\end{array}$ & $\begin{array}{c}\text { failure strain } \\
\text { for } \\
\text { noncharged }\end{array}$ & $\begin{array}{c}\text { Strain } \\
\text { rate } \\
\left(\mathrm{s}^{-1}\right)\end{array}$ & $\begin{array}{c}\text { Temp. } \\
\left({ }^{\circ} \mathrm{C}\right)\end{array}$ & $\begin{array}{c}\text { Diffusivity } \\
\left(\mathrm{cm}^{2} / \mathrm{s}\right)\end{array}$ & $\begin{array}{c}\text { strain rate/ } \\
\text { Diffusivity }\end{array}$ \\
\hline 13.5 & 13.5 & $3.33 \times 10^{-4}$ & -196 & $7.1 \times 10^{-37}$ & $4.7 \times 10^{32}$ \\
\hline 5 & 23 & $3.33 \times 10^{-4}$ & -25 & $7.8 \times 10^{-12}$ & $4.3 \times 10^{7}$ \\
\hline 3.5 & 23 & $5 \times 10^{-5}$ & -25 & $7.8 \times 10^{-12}$ & $6.4 \times 10^{8}$ \\
\hline 4.7 & 21 & $3.33 \times 10^{-3}$ & 25 & $4.2 \times 10^{-10}$ & $7.9 \times 10^{6}$ \\
\hline 3.5 & 21 & $3.33 \times 10^{-4}$ & 25 & $4.2 \times 10^{-10}$ & $7.9 \times 10^{5}$ \\
\hline 2.6 & 21 & $3.33 \times 10^{-5}$ & 25 & $4.2 \times 10^{-10}$ & $7.9 \times 10^{4}$ \\
\hline 3.6 & 21 & $3.33 \times 10^{-4}$ & 65 & $4.3 \times 10^{-9}$ & $7.6 \times 10^{4}$ \\
\hline 6.5 & 23 & $3.33 \times 10^{-4}$ & 175 & $3.1 \times 10^{-7}$ & $1.1 \times 10^{3}$ \\
\hline 13.5 & 30 & $3.33 \times 10^{-4}$ & 285 & $4.2 \times 10^{-6}$ & $8.0 \times 10^{1}$ \\
\hline
\end{tabular}

It has been shown that the failure strain is a combination of the strain to initiate the voids and the strain to grow the voids until the voids coalesce (15). The growth of the voids is proportional to the ratio of the void size to the size of the voidinitiating particles. Since the particles that are nucleating the voids are not changing due to the hydrogen charging and the final void size did not change, the strain for void growth was considered constant. This suggests that the parameter that is controlling the fracture strain is the strain to initiate the voids. Though, a locally increased rate of void growth can not be discounted as an embrittling mechanism.

The strain rate had very little effect on the fracture behavior of the noncharged specimens. The ultimate strength and elongation showed no noticeable change as the strain rate was decreased. For the hydrogen charged specimens, the elongation was reduced as the strain rate decreased. The elongation was decreased from $5.2 \%$ to $2.9 \%$ for a specimen with $65 \mathrm{ppm}$ hydrogen as the strain rate was decreased from $3.33 \times 10^{-3}$ to $3.33 \times 10^{-5} \mathrm{~s}^{-1}$ at $25^{\circ} \mathrm{C}$. This difference shows that hydrogen diffusion is needed for the embrittlement of this superalloy.

The effect of temperature on failure strain is represented schematically in Figure 3.1.4. As the temperature was decreased below $65^{\circ} \mathrm{C}$, the ductility of the hydrogen charged specimens increased while that of the noncharged specimens decreased. In fact, at $-196^{\circ} \mathrm{C}$, hydrogen did not degrade the mechanical properties. It should be noted that the diffusion of hydrogen to the high hydrostatic stress region could not explain these results. Separate tensile testing at $25^{\circ} \mathrm{C}$ of a specimen charged with only $5.7 \mathrm{ppm}$ hydrogen failed at $7.3 \%$ elongation. If diffusion to the hydrostatic stress region described the fracture process, then it would be expected that the specimen with $65 \mathrm{ppm}$ hydrogen tested in liquid nitrogen would be embrittled at least as much as the specimen charged to $5.7 \mathrm{ppm}$ hydrogen.

As the temperature was increased above $65^{\circ} \mathrm{C}$ the ductility also increased, though, embrittlement was observed to $285^{\circ} \mathrm{C}$. Since the embrittlement was observed as high as $285^{\circ} \mathrm{C}$, the trapping at grain boundary carbides may also be very important since dislocation trapping is not very effective at this temperature with an activation energy of $0.1 \mathrm{eV}(12)$.

A minimum in ductility as a function of temperature as was observed suggests that there are two competing processes that influence the embrittlement. The first process is diffusion which is enhanced as the temperature is increased. As diffusion is increased, more hydrogen is supplied to the location of crack initiation. The 
second process is the trapping of hydrogen at defects. The trapping potential is decreased as temperature is increased. In order to separate these two processes, the strain rate was normalized with respect to the diffusivity for the specimens with $65 \mathrm{ppm}$ hydrogen. The results are displayed in Table 3.1.1.

A comparison of the failure strain of specimens that had the same ratio of strain rate to hydrogen diffusivity reveals that as the temperature is decreased, the embrittlement becomes more severe. This was examined by comparing tests at $-25^{\circ} \mathrm{C}$ and $25^{\circ} \mathrm{C}$ as well as specimens at $25^{\circ} \mathrm{C}$ and $65^{\circ} \mathrm{C}$. There is very little trapping at over $65^{\circ} \mathrm{C}$ and the effect of trapping on embrittlement and the embrittlement itself is less pronounced over $65^{\circ} \mathrm{C}$. In those cases, the diffusion is much quicker than at $25^{\circ} \mathrm{C}$ yet the embrittlement is less severe. Above $65^{\circ} \mathrm{C}$ the ductility of the noncharged specimens was slightly increased while the ductility of the hydrogen-charged specimens as portrayed in Figure 3.1.4. As has been discussed in previous papers $((13),(16))$ hydrogen transport by dislocations may be important.

\subsection{Effect of Prestrain on Fracture}

If the embrittlement mechanism is one related to the local plasticity, local yielding would be required for the embrittlement. To confirm that plastic deformation was required for the fracture in hydrogen-charged specimens, the specimens were strained prior to hydrogen-charging thereby increasing the flow stress. After the hydrogen-charging, the specimens were strained to failure. Table 3.2.1 displays the data on the specimens that were strained prior to hydrogen-charging and subsequent tensile tested. The stress strain curves are shown in Figure 3.2.1

TABLE 3.2.1 EFFECT OF PRESTRAIN ON THE FRACTURE BEHAVIOR AT $25^{\circ} \mathrm{C}$

\begin{tabular}{|c|c|c|c|c|c|}
\hline \hline $\begin{array}{c}\text { Strain rate } \\
\left(\mathrm{s}^{-1}\right)\end{array}$ & $\begin{array}{c}\text { Strain } \\
\text { prior to } \mathrm{H} \\
\text { charging }\end{array}$ & $\begin{array}{c}\text { True stress } \\
\text { prior to } \mathrm{H} \\
\text { charging } \\
\text { (MPa) }\end{array}$ & $\begin{array}{c}\text { Hydrogen } \\
\text { concentration } \\
(\mathrm{ppm})\end{array}$ & $\begin{array}{c}\text { Plastic } \\
\text { failure } \\
\text { strain after } \\
\text { charging }\end{array}$ & $\begin{array}{c}\text { True } \\
\text { failure } \\
\text { stress } \\
\text { after } \\
\text { charging }\end{array}$ \\
\hline \hline $3.33 \times 10^{-4}$ & 0 & 0 & 65 & $3.5 \%$ & 983 \\
\hline $3.33 \times 10^{-4}$ & $1.6 \%$ & 871 & 65 & $2.5 \%$ & 980 \\
\hline $3.33 \times 10^{-4}$ & $5 \%$ & 1019 & 65 & $0.6 \%$ & 1041 \\
\hline $3.33 \times 10^{-4}$ & $10 \%$ & 1182 & 65 & $0.2 \%$ & 1170 \\
\hline
\end{tabular}

The specimen plastically prestrained to $1.6 \%$ prior to hydrogen charging failed after an additional $2.5 \%$ plastic strain following the charging. The fracture stress was the same as the fracture stress for the nonprestrained specimen while the total strain (prestrain added to the strain after charging) was slightly higher than the nonprestrained specimen. This suggests that a critical stress, critical strain, or a combination of stress and strain is needed for fracture. The specimen prestrained to $1.6 \%$ showed a yield point phenomenon after the hydrogen charging. This was expected since the temperature for hydrogen charging is in the range where Alloy $X-750$ exhibits dynamic strain aging. The specimens that were prestrained to $5 \%$ or $10 \%$ failed near the flow stress, i.e., the final stress applied to the specimen during the prestraining. Since minimal plasticity was observed in these specimens, there would have been little transport of hydrogen due to dislocation transport. The stress on the specimens decreased during the plastic deformation due to the yield point phenomenon. This suggests that the final fracture was not due to achieving a critical stress. Further, the plastic deformation was limited and little dislocation 
transport of hydrogen would have occurred. In all cases prestraining increased the critical fracture load to at least the flow stress. This showed that in the presence of hydrogen some amount macroscopic plasticity and more important, local plasticity, was essential for ductile intergranular fracture. The fracture surfaces of all the specimens in this prestrain experiment were intergranular with dimples on the surface. No change in the fracture surface morphology or the void size was evident. This point is illustrated in Figure 3.2.2, which shows the fracture surface of the specimen prestrained to $10 \%$. It is possible that local plasticity near the grain boundary due to local hydrogen enrichment caused the lower ductility since the fracture morphology of hydrogen charged and noncharged specimens was similar.

\subsection{Fracture Toughness Properties}

As stated in the experimental procedure, the fracture toughness of the hydrogencharged specimens was determined by using linear-elastic fracture toughness testing while for the noncharged specimens elastic-plastic fracture toughness testing was employed. The results from the fracture-toughness testing are displayed in Table 3.3.1. The measured fracture toughness of the hydrogen-charged specimens were valid $K_{\mathrm{lc}}$ values. The noncharged specimen data was analyzed in order to calculate $\mathrm{K}_{\mathrm{Jc}}$ as determined from ASTM E813-81 while $\mathrm{J}$ was determined from the 1987 specification.

TABLE 3.3.1 FRACTURE TOUGHNESS PROPERTIES OF HTH ALLOY X-750

\begin{tabular}{|c|c|c|c|c|c||}
\hline $\begin{array}{c}\text { Hydrogen } \\
\text { conc. }(\mathrm{ppm})\end{array}$ & $\begin{array}{c}\text { Loading Rate } \\
(\mathrm{MPa} \text { m/s })\end{array}$ & $\begin{array}{c}\mathrm{K}_{\mathrm{lc}} \text { or } \mathrm{K}_{\mathrm{a}} \\
(\mathrm{MPa} \text { ) }\end{array}$ & $\begin{array}{c}\text { Valid per ASTM } \\
\text { E399 }\end{array}$ & $\begin{array}{c}\mathrm{K}_{\mathrm{Jc}} \\
(\mathrm{MPa} / \mathrm{m})\end{array}$ & $\begin{array}{c}\text { Valid per } \\
\text { ASTM E813 }\end{array}$ \\
\hline 0 & .11 & -- & No & 161 & Yes \\
\hline 40 & .055 & 53 & Yes & -- & -- \\
\hline 65 & .55 & 52 & Yes & -- & -- \\
\hline 65 & .055 & 45 & Yes & -- & -- \\
\hline 65 & 0.011 & 42 & Yes & -- & -- \\
\hline
\end{tabular}

The fracture toughness was dramatically decreased by hydrogen charging the specimens. The fracture toughness was reduced from $161 \mathrm{MPa} \vee \mathrm{m}$ with no hydrogen to as low as $42 \mathrm{MPa} / \mathrm{m}$ with $65 \mathrm{ppm}$ hydrogen. The loading rate had a large effect on the toughness of the hydrogen charged specimens, as shown in TABLE 3.3.1, $\mathrm{K}_{\mathrm{lc}}$ decreased from $52 \mathrm{MPa} / \mathrm{m}$ when loaded quickly to $42 \mathrm{MPa} / \mathrm{m}$ when loaded slowly.

In Alloy $X-750$ the fracture toughness of specimens, $K_{\mathrm{lc}}$ is approximately the same as the threshold value determined from a constant displacement test using a bolt-loaded specimen. The fracture toughness of a specimen with $40 \mathrm{ppm}$ hydrogen was $53 \mathrm{MPa} / \mathrm{m}$. A specimen with $40 \mathrm{ppm}$ hydrogen was quickly bolt loaded to 57 $\mathrm{MPa} / \mathrm{m}$. The crack growth rate was initially $2.5 \times 10^{-8} \mathrm{~m} / \mathrm{s}$ but rapidly decreased to $2.5 \times 10^{-8} \mathrm{~m} / \mathrm{s}$ at $49 \mathrm{MPa} / \mathrm{m}$. At $48 \mathrm{MPa} / \mathrm{m}$ no cracking was observed. The 48 $\mathrm{MPa} / \mathrm{m}$ is slightly below the observed fracture toughness measured on the rising load specimen at $0.055 \mathrm{MPa} / \mathrm{m} / \mathrm{s}$.

Scanning electron microscopy was used to analyze the fracture morphology. The fractographic features of the fracture toughness specimens were similar to the tensile specimens. In noncharged specimens, there was a a small amount of transgranular microvoid coalescence with predominantly intergranular microvoid coalescence. The transgranular dimples were much larger than the intergranular dimples. The addition of hydrogen appears to have also slightly reduced the size of the intergranular voids. The resulting fracture surface was similar to the typical ductile dimple fracture. 


\subsection{Mechanism}

The ductile intergranular fracture process in HTH Alloy $X-750$ was by microvoid coalescence. The microvoid initiation sites appear to be the grain boundary carbides as determined from the size and spacing of the microvoids as well as upon plateau etching. The final void size measured from tensile specimens was not affected by the hydrogen while the failure strain was reduced from $21 \%$ to under $3 \%$ suggesting that the role of hydrogen may be to decrease the void initiation strain. No necking was observed in either case. The void growth process does not appear to be significantly altered by the hydrogen. Though, a locally increased rate of void growth can not be discounted as an embrittling mechanism since void growth and coalescence require local plastic deformation. The requirement for local plastic deformation was exhibited by the prestrain experiments.

A reduction in the cohesive energy of the carbide-matrix interface or the build up of a local hydrogen pressure at the carbide-matrix interface are consistent with the results. In either of these cases, the strain to initiate the voids would be decreased resulting in the strain to failure decreasing. The behavior at $-196^{\circ} \mathrm{C}$ suggests that the HELP mechanism may also play a role in the fracture process, since at this temperature there is no degradation and no interaction between the hydrogen and dislocations. If the phenomenon were due only to a decrease in the void initiation strain by a reduction in the bond strength, one would expect some amount of embrittlement even at this low temperature. This further shows that at least two embrittling mechanisms are operating in this system.

It is envisioned that the role of the local hydrogen concentration and the effect of hydrogen on the bonding is to reduce the effective surface energy, $Y_{S E} \cdot \gamma_{S E}$ is defined as $\gamma_{s}+y_{p}$, where $y_{g}$ is the interfacial surface energy and $y_{p}$ is the plastic energy used in creating the new surfaces. Hydrogen is expected to reduce both parameters.

The relation between the changes in ductility and the fracture topography for ductile fracture for void initiation was discussed by Thompson (15). Thompson discussed two ways ductility could be altered by modifying the void initiation event. One method was to reduce the strain to initiate the void while maintaining a constant density of void nuclei. The other method was to keep the initiation strain approximately constant and to increase the number of void nuclei. In the first case, the void size should not be affected while the fracture strain should be reduced. This is what was observed in the testing discussed in this paper. The second possibility would result in a decrease in void size as well as in ductility. In this material, a majority of the possible void nucleating particles appear to initiate the voids even in the noncharged state. This is shown by the average void size without hydrogen being $0.4 \mu \mathrm{m}$ and the grain boundary carbide size between $0.1 \mu \mathrm{m}$ and 0.3 $\mu \mathrm{m}$. The final void size in the specimens charged with hydrogen was also $0.4 \mu \mathrm{m}$. There appears not to be a single mechansim for the embrittlement. A reduction in the cohesive energy of the carbide-matrix interface and the HELP mechanism are consistent with the results. The build up of a local hydrogen pressure at the carbidematrix interface is also a possibility. In these cases, the macroscopic strain to initiate the voids would be decreased. It is also expected that the void initiation strain without hydrogen is well over $3 \%$ strain which further supports the reduction in void initiation strain as the embrittlement phenomena. Though, the results can not refute an enhanced rate of void growth and this may occur as well.

\subsection{SUMMARY}

Hydrogen degrades the mechanical properties of HTH Alloy X-750. Hydrogen charged specimens are degraded more as the strain rate is decreased while no change was observed for noncharged specimens. This result is consistent with the 
need for hydrogen interaction with dislocations.

It was also shown that prestraining prior to charging drastically decreased elongation. Specimens strained to $5 \%$ and $10 \%$ plastic strain followed by charging and then strained at a rate of $3.33 \times 10^{-4} \mathrm{~s}^{-1}$, showed a small amount of elongation. This is consistent with the need for some local plasticity prior to failure and is consistent with the HELP mechanism for the embrittlement. These data were also consistent with a reduction in the strength of the matrix-carbide interface.

The fracture morphology of all the specimens was intergranular microvoid coalescence. A mechanism of hydrogen reducing the void initiation strain by decreasing the cohesive energy between the grain-boundary carbides and the nickel matrix are consistent with the most of the observed behavior. The prestrain data was consistent with the HELP mechanism. Hydrogen pressurization at the carbidematrix interface and an increase in the rate of void growth can not be refuted as embrittlement mechanisms. It is proposed that more than one mechanism is acting to embrittle this material.

\subsection{REFERENCES}

(1) I. M. Robertson and H. K. Birnbaum, Acta Met., 34, 1986, p. 353

(2) D. Shih and H. K. Birnbaum, in Modelling Environmental Effects on Crack Growth Processes, Eds. R. H. Jones and W. Gerberich, (TMS, New York, 1986), p. 355

(3) W. S. Walston, The Effect of Hydrogen and Microstructure on the Deformation and Fracture Behavior of a Single Crystal Nickel-Base Superalloy, Ph.D. Thesis, Carnegie Mellon University, dated April, 1990

(4) W. S. Walston, I. M. Bernstein, and A. W. Thompson, "The Effect of Hydrogen on a Single-Crystal Nickel-Base Superalloy", Met. Trans., Vol. 23A, pp. 1313-1322

(5) N. R. Moody, R. E. Stoltz, and M. W. Perra, "The Effect of Hydrogen on Fracture Toughness of the Fe-Ni-Co Superalloy 903, Met. Trans., Vol. 18A, 1987, pp. 1469-1482

(6) N. R. Moody, S. L. Robinson, and M. W. Perra, "Internal Hydrogen Effects on Thresholds for For Crack Growth in the Iron-Based Superalloy IN903", Eng. Frac. Mech., Vol. 39, No. 6, 1991, pp. 941-954

(7) E. A. Steigerwald, F. W. Schaller and A. R. Troiano, Trans. Met. Soc. AIME, 218, 1960, p. 832

(8) R. A. Oriani and P. H. Josephic, Acta Met, 22, 1974, p. 1065

(9) C. D. Beachem, Met. Trans., 3A, 1972, p. 437

(10) J. Eastman, T. Matsumoto, N. Narita, F. Heubaum, and H. K. Birnbaum, in Hydrogen Effects in Metals, Eds. A. W. Thompson and I. M. Bernstein, (Warrendale, PA), p. 397, 1986

(11) J. C. Chesnutt and R. A. Spurling, Met. Trans, 8A, 1977, 216-218

(12) J. E. Angelo, N. R. Moody, and M. I. Baskes, "Hydrogen-Dislocation Interactions In NI - An Atomistic Study, Fifth Internation Conference on Hydrogen Effects on Materials Behavior

(13) P. Bastien and P. Azou, C. R. Acad. Sci. Paris, 1951, Vol. 232, pp. 1845-1848

(14) L. M. Brown and J. D. Embury, "The Initiation and Growth of Voids at Second Phase Particles" in Proc. of Third Int. Conf. on Strength of Metals and Alloys, Iron and Steel Inst., London, 1973, p. 164

(15) A. W. Thompson, Acta. Met., Vol. 31, No. 10, pp. 1517-1523, 1983

(16) J. K. Tien, A. W. Thompson, I. M. Bernstein, and R. J. Richard, Met. Trans., Vol. 7A, June 1976, pp. 821-829

\subsection{ACKNOWLEDGEMENTS}

This work was supported by DOE contract DE-AC11-93PN38195. 


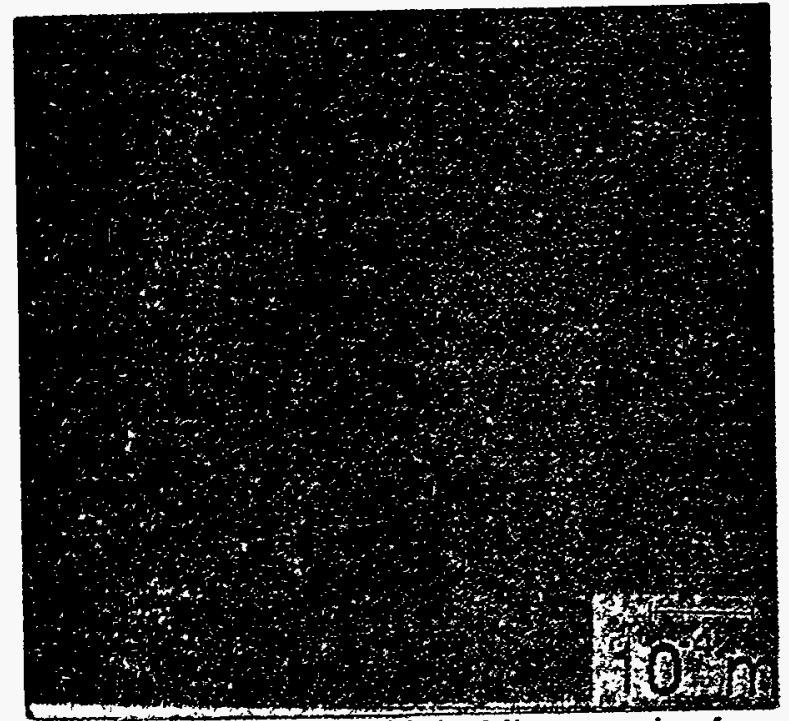

Figure 2.1 Light Micrograph of Alloy $X-750$

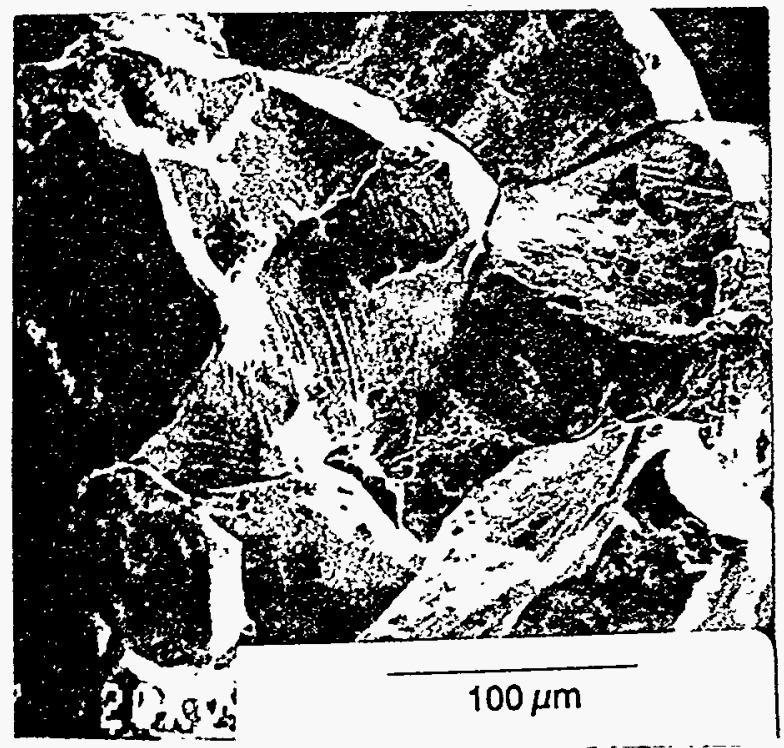

Figure 3.1.1a Fractography of Noncharged Tensile Specimen

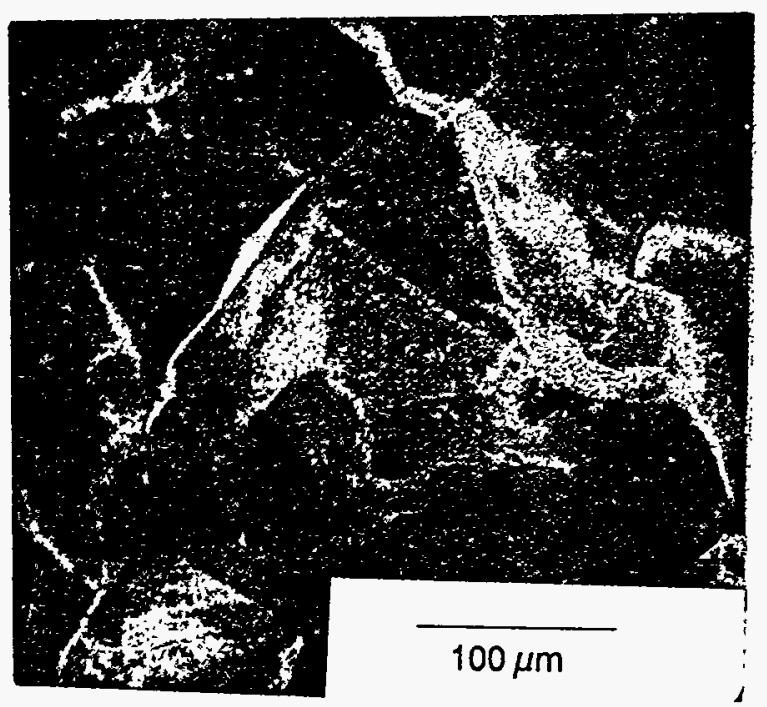

Figure 3.1.2a Fractography of Hydrogen Charged Tensile Specimen

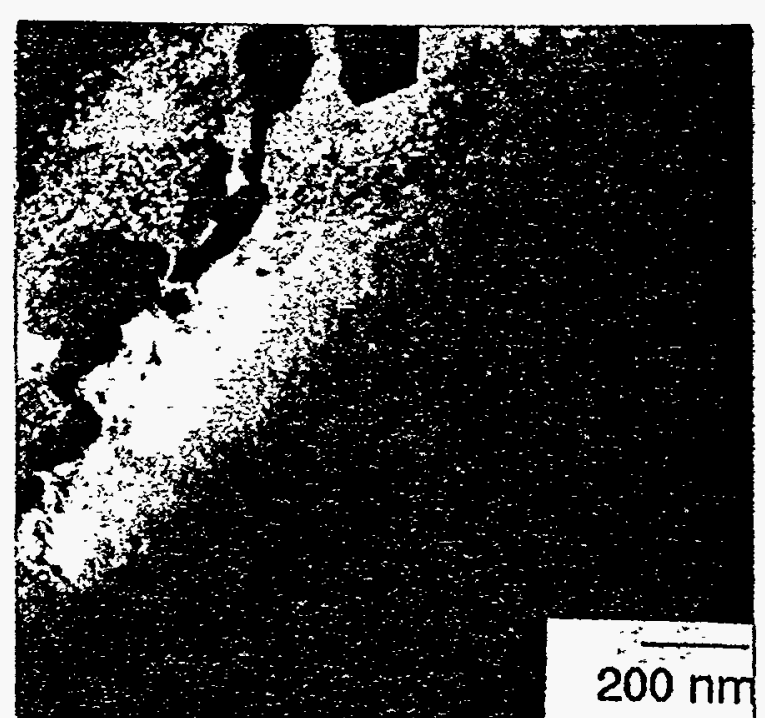

Figure 2.2 TEM Micrograph of Alloy $X-750$ Showing Fine Scale Structure

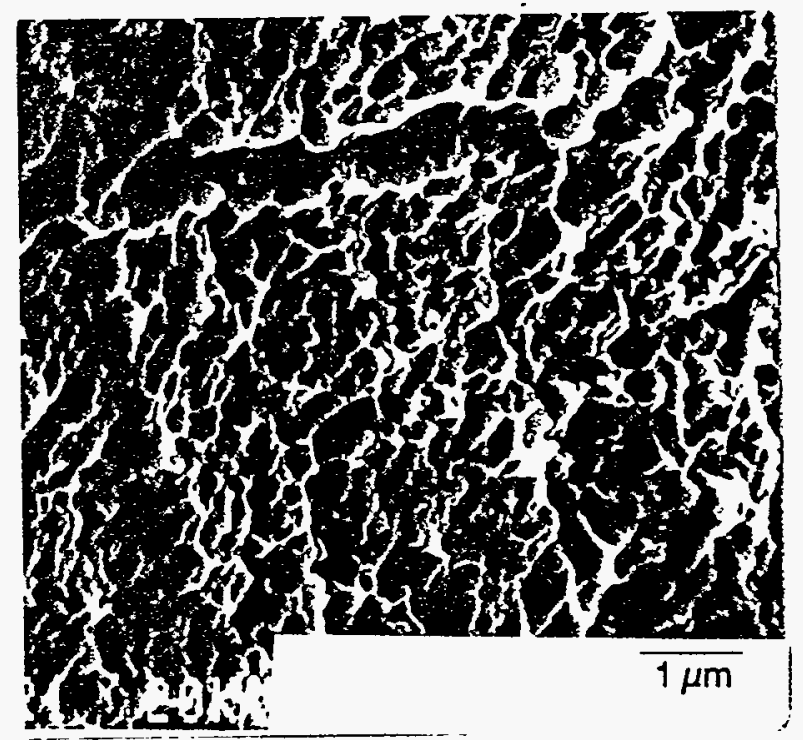

Figure 3.1.1b Fractography of Noncharged Tensile Specimen

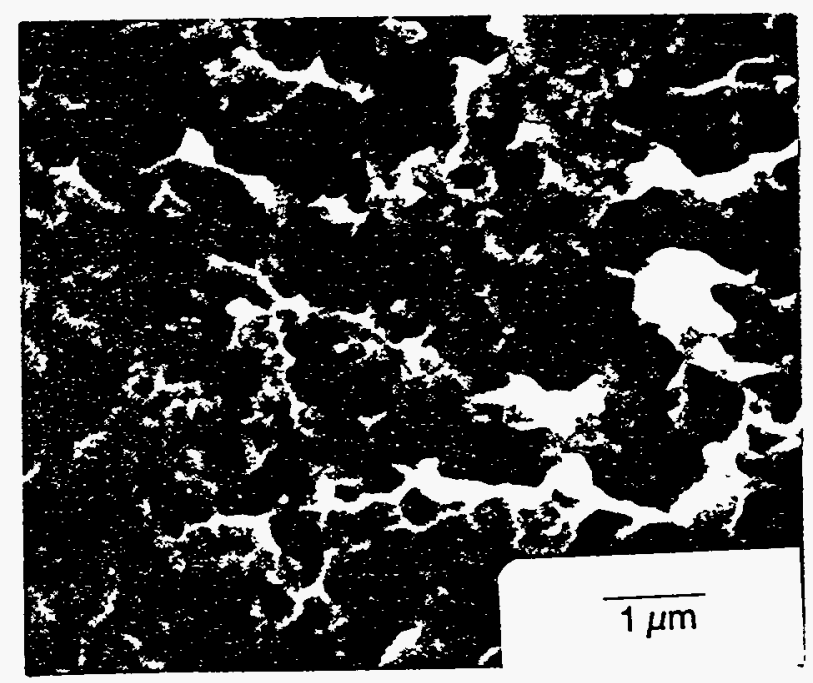

Figure 3.1.2b Fractography of Hydrogen Charged Tensile Specimen 


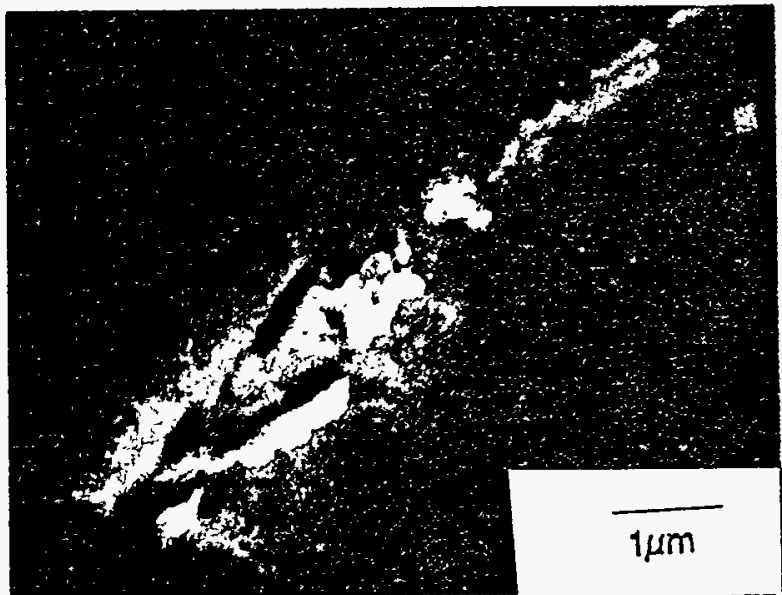

Figure 3.1.3 Hydrogen Charged Specimen Void Nucleating at $\mathrm{M}_{23} \mathrm{C}_{6}$

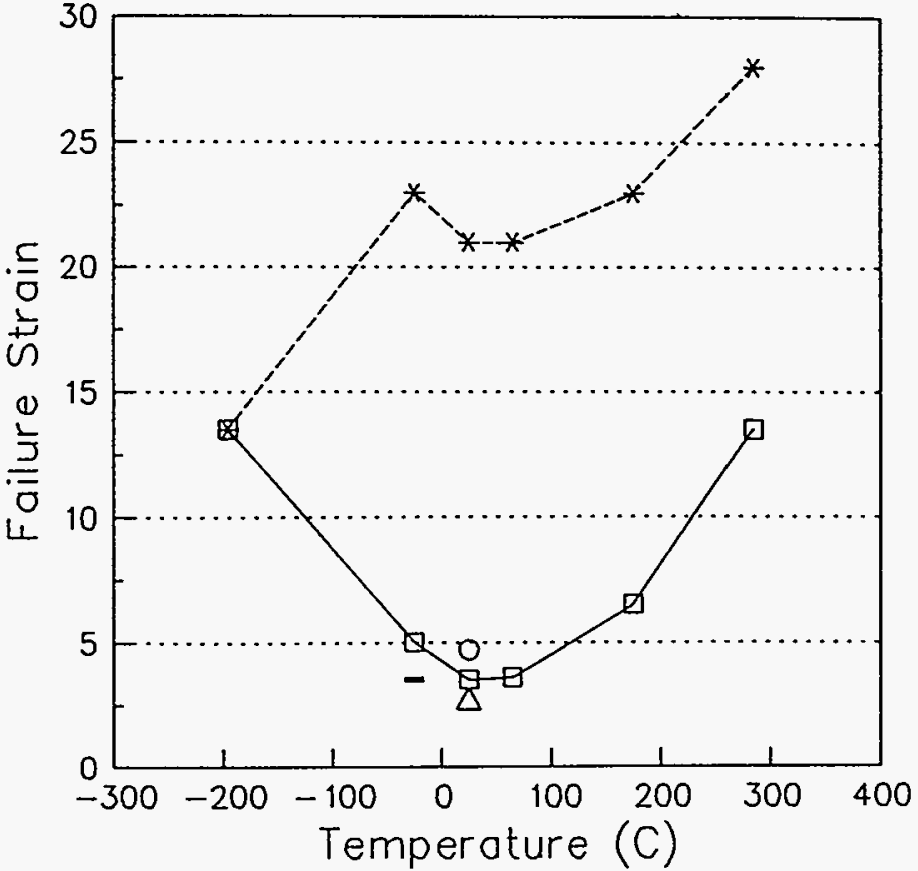

Hydrogen charged Hydrogen charged Hydrogen charged
$3.33 \mathrm{E}-4 / \mathrm{s}$
$-\mathrm{B}$
$3.33 E-5 / s$
$3.33 E-3 / s$

Hydrogen charged No Hydrogen

$$
5 E-5 / \mathrm{s} \quad 3.33 E-4 / \mathrm{s}
$$

FIGURE 3.1.4 Effect of Temperature and Strain Rate on the Fracture Behavior

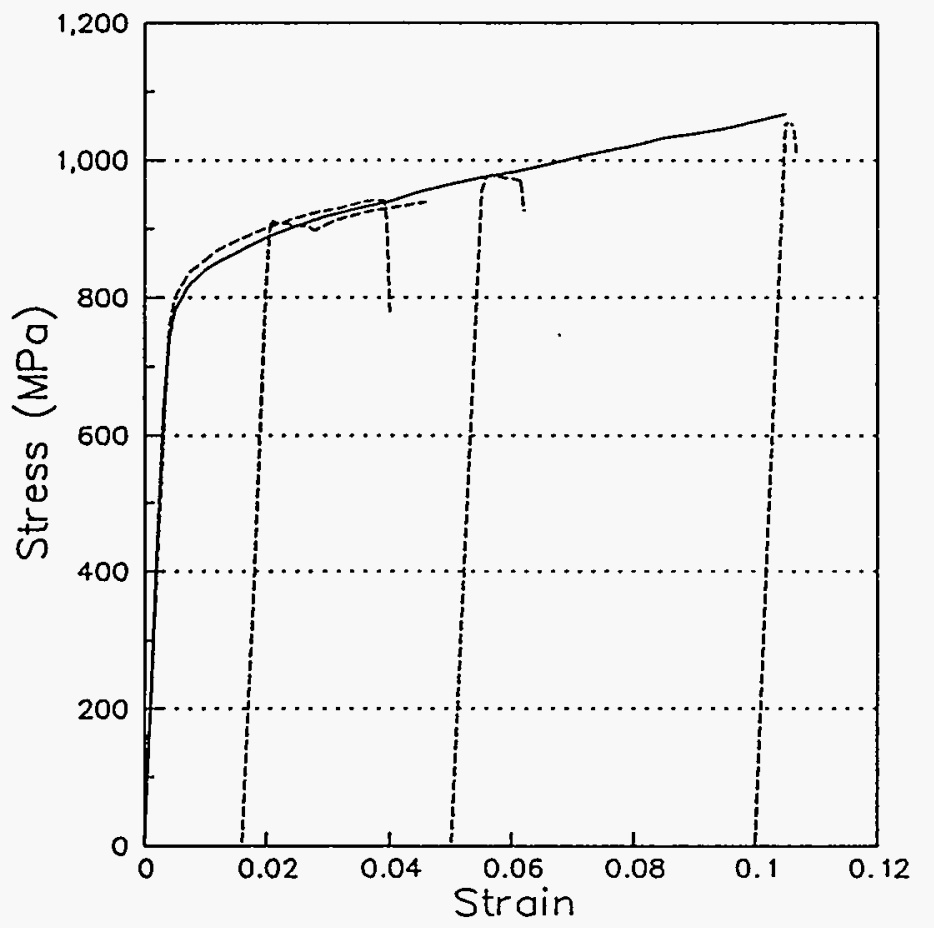

$\begin{array}{lr}\text { Prestrain } & \text { strain rate } \\ \text { curve } & 3.33 \times 10^{-4} \\ & \text { sec }^{-1}\end{array}$

FIGURE 3.2.1, Effect of Prior Deformation on the Fracture Behavior

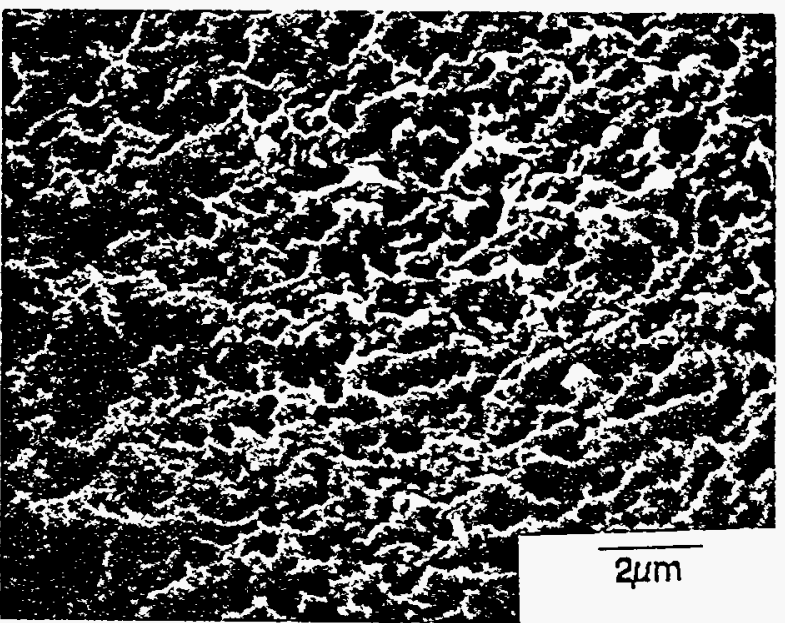

FIGURE 3.2.2 Specimen Prestrained 10\% prior to Hydrogen Charging 